\title{
Penerapan Metode AHP Pada Pemilihan Kosmetik Yang Tepat Untuk Siswi SMA
}

\author{
Fajar Agustini ${ }^{1}$ \\ ${ }^{1}$ AMIK BSI Karawang \\ e-mail: fajar.fgt@bsi.ac.id
}

\begin{abstract}
Abstrak
Perkembangan industri kosmetik yang terus meningkat menyebabkan beragamnya produk kosmetik yang beredar di pasaran, baik dari segi merek, fasilitas, jenis, harga maupun varian lainnya yang terkandung dalam produk tersebut. Kulit wajah adalah bagian terpenting dari penampilan seorang wanita untuk menjaga agar kulit selalu terlihat halus dan sehat. Komposisi kosmetik merupakan salah satu hal yang penting diperhatikan saat memilih kosmetik, salah satu kebijakan dan peraturan yang di rancang untuk melindungi dan memudahkan konsumen adalah kewajiban produsen untuk mencantumkan semua bahan-bahan komposisi dari kosmetik tersebut, komposisi pada kosmetik bias berperan sebagai media informasi bagi konsumen untuk memperoleh kepercayaan terhadap produk kosmetik tersebut. Berdasarkan hal tersebut, penulis merancang sistem penerapan metode Analytical Hierarchy Process (AHP) dan software Expert Choice di SMA Taman Harapan. Hasil penelitian ini menunjukkan bahwa sistem yang di bangun mampu memberikan hasil perhitungan secara otomatis sesuai dengan hasil perhitungan yang dilakukan secara manual. Diharapkan dengan metode ini dapat membantu pengambilan keputusan yang bersifat objektif dan pada proses pemilihan kosmetik yang tepat yang lebih efisien.
\end{abstract}

Kata Kunc: Kepuasan, Konsumen, Kualitas, Produk, AHP

\begin{abstract}
The increasing development of the cosmetic industry has caused a variety of cosmetic products on the market, both in terms of brands, facilities, types, prices and other variants contained in the product. Facial skin is the most important part of a woman's appearance to keep the skin looking smooth and healthy. Cosmetic composition is one of the important things to consider when choosing cosmetics, one of the policies and regulations designed to protect and facilitate consumers is the manufacturer's obligation to list all the ingredients of the cosmetics, the composition of cosmetics can act as a medium of information for consumers to gain trust in these cosmetic products. Based on this, the authors designed a system for applying the Analytical Hierarchy Process (AHP) method and Expert Choice software at Taman Harapan High School. The results of this study indicate that the system in the wake is able to give the results of calculations automatically in accordance with the results of calculations performed manually. It is expected that this method can help make decisions that are objective and in the process of selecting the best cosmetics that are more efficient.
\end{abstract}

Keywords: Satisfaction, Consumer, Quality, Product, $A H P$

\section{Pendahuluan}

Kosmetik merupakan salah satu kebutuhan manusia yang sudah ada dan semakin berkembang dari waktu ke waktu, perkembangan ilmu kosmetik serta industrinya baru di mulai secara besarbesaran pada abad ke 20 dan kosmetik menjadi salah satu bagian dari dunia usaha. Kecantikan dan keindahan wajah merupakan dambaan dan daya Tarik tersendiri bagi setiap orang. Selain untuk membuat penampilan menarik, perawatan wajah juga penting untuk kesehatan kulit wajah. (Penelitian \& Pengaruh, 2013)

Kulit wajah adalah bagian terpenting dari penampilan seorang wanita. Untuk menjaga agar kulit selalu terlihat putih, halus, dan sehat ada banyak cara. Gaya hidup kini yang terjadi pada masyarakat baik masyarakat kota maupun desa, tidak hanya dikalangan anak remaja tetapi juga dikalangan orang dewasa. Hal tersebut membuat para produsen kosmetik berlombalomba mempromosikan produknya, salah satunya melalui iklan. (Permata et al., 2017) 
Komposisi kosmetik merupakan salah satu hal yang penting diperhatikan saat memilih kosmetik. Salah satu kebijakan dan peraturan yang di rancang untuk melindungi dan memudahkan konsumen adalah kewajiban produsen untuk mencantumkan semua bahan-bahan komposisi dari kosmetik tersebut. Komposisi pada kosmetik bisa berperan sebagai media informasi bagi konsumen untuk memperoleh kepercayaan terhadap produk tersebut. (Fachrurrazi et al., n.d.).

Metode yang akan dipakai dalam pengambilan keputusan pemilihan kosmetik yang tepat ini adalah Analitical Hierarchy Process (AHP). Hal ini di karenakan metode AHP mampu memecah-mecahkan suatu situasi yang kompleks, tak terstruktur ke dalam bagian-bagian komponennya, menata bagian atau variabel dalam suatu susunan hirarki, memberi nilai numerik pada pertimbangan subyektif tentang relatif pentingnya di setiap variabel, dan mensintesiskan berbagai pertimbangan ini untuk menetapkan variabel mana yang memiliki prioritas paling tinggi dan bertindak untuk mempengaruhi pada suatu situasi. (Handayani, 2016).

\section{Metode Penelitian}

\section{a. Sistem}

Menurut Murdick dalam Ladjamudin (2005) "Sistem sebagai seperangkat elemen-elemen yang terintegrasi dengan maksud yang sama untuk mencapai suatu tujuan berasama".Suatu sistem adalah jaringan kerja dari prosedur yang saling berhubungan, berkumpul bersama-sama untuk melakukan suatu kegiatan atau untuk menyelesaikan suatu sasaran yang tertentu (Jogiyanto, 2005). Pendekatan sistem yang merupakan jaringan kerja dari prosedur lebih menekankan urut-urutan operasi didalam sistem. Prosedur didefiniasikan oleh Richard F. Neuschel sebagai berikut: suatu uruturutan operasi klerikal (tulis menulis), biasanya melibatkan beberapa orang satu atau lebih departemen yang diterapkan untuk menjamin penanganan yang seragam dari transaksi-transaksi yang terjadi.

b. Kosmetik

Menurut (Rahmawati, 2014) Kosmetik merupakan sebuah produk yang unik karena selain memiliki kemampuan untuk memenuhi kebutuhan mendasar wanita akan kecantikan, seringkali menjadi sarana bagi konsumen untuk memperjelas identitas dirinya secara sosial dimata masyarakat. Seiring perkembangan zaman, kosmetik seolah menjadi kebutuhan primer bagi sebagian kaum wanita. Produk kosmetik sesungguhnya memiliki resiko pemakaian yang perlu diperhatikan mengingat kandungan bahan-bahan kimia tidak selalu memberi efek yang sama untuk setiap konsumen. Definisi kosmetik dalam Peraturan Menteri Kesehatan RI No. 220/MenKes/Per/X/1976 tanggal 6 september 1976 yang menyatakan bahwa kosmetika adalah bahan atau campuran bahan untuk digosokkan, dilekatkan, dituangkan, dipercikan, atau disemprotkan. Tujuan penggunaan kosmetik ini adalah untuk merawat kebersihan dan kesehatan kulit, kosmetik perawatan kulit terdiri dari kosmetik pembersih kulit (cleanser), kosmetika pelembab kulit (moisturizer), kosmetika pelindung kulit dan kosmetika untuk menipiskan kulit (peeling), contoh dari kosmetika perawatan kulit adalah sabun, night cream, sunscreen cream, scrub cream. Konsumen dari produk komestik sangat beragam. Salah satunya ialah wanita muslimah. Namun salah satu kendala bagi muslimah ialah kualitas dan bahan yang digunakan dari make up tersebut, diantaranya unsur kehalalan produk.

\section{c. Penggunaan Kosmetik}

Adapun cara dan penggunaan kosmetik itu berbeda-beda. Ada yang di gosokkan, dipercikkan, atau disemprotkan pada bagian tertentu. Kegunaannya ada yang untuk membersihkan wajah, untuk memelihara dan menambah daya Tarik. Menurut permenkes RI (1976). Kosmetik adalah bahan atau campuran bahan untuk digosokkan, dilekatkan, dituangkan, di percikkan di bagian tertentu. Dalam memakai kosmetik, konsumen hendaknya 
harus teliti dan tahu betul, jangan sampai keliru, karena jika terjadi kekeliruan nanti berakibat fatal terhadap kulit bahkan mungkin ke organ tubuh yang mestinya di gosokkan sampai di oleskan pada wajah dan seterusnya, sehingga benar-benar memperoleh hasil yang memuaskan dan sesuai yang diinginkan. (Indika \& Lainufar, 2015).

\section{d. Komposisi Kosmetik}

Komposisi adalah kandungan zat-zat serta jumlahnya yang harus terdapat di dalam suatu produk (MUI,2001). Tujuan mengetahui komposisi kandungan bahan kosmetik dan mencermati formulasi bahan tidak lain adalah agar terhindar dari reaksi negatif bahan-bahan kosmetik yang berbahaya bagi tubuh. Dasar kandungan kosmetik terdiri dari bermacam-macam bahan dasar, bahan aktif dan bahan pelengkap. Bahan-bahan tersebut mempunyai aneka fungsi yaitu sebagai, pelarut, pencampur, pengawet, pelekat, pengencang, penyerap dll. Pada umumnya $95 \%$ dari kandungan kosmetika adalah bahan dasar $5 \%$ bahan aktif atau kadang-kadang tidak mengandung bahan aktif. Hal ini mengandung arti bahwa kosmetik sifat dan efeknya tidak ditentukan oleh bahan aktif tetapi terutama oleh bahan dasar kosmetika tersebut. (Rahmawati, 2014). Berikut yang perlu diperhatikan adalah bahanbahan yang berbahaya pada kosmetik dan sudah mengeluarkan peringatan publik oleh BPOM, yaitu :
a. Merkuri
b. Hidrokinon
c. Asam retinoat
d. Bahan pewarna merah

\section{e. Penerapan Metode AHP}

Menurut, (Taufiq \& Fahrozi, 2016) Penerapan Metode AHP adalah metode yang digunakan untuk menilai sebuah studi kasus yang dalam penyelesaianya lebih mengutamakan penilaian relatif. Dengan menggunakan metode AHP nilai relatif tersebut di transformasi juga menjadi nilai kuantitatif. Dengan nilai kuantitatif tersebut, maka penilaian bias di katakan lebih objektif karena menggunakan nilai berdasarkan perhitungan metode.

\section{f. AHP}

Menurut, (Taufiq \& Fahrozi, 2016)

Metode AHP dikembangkan oleh Thomas L. Saaty sekitar tahun 1970an untuk mengorganisasikan informasi dan judgment dalam memilih alternatif yang paling disukai. Dengan menggunakan AHP, suatu persoalan yang akan dipecahkan dalam suatu kerangka berpikir yang terorganisir, sehingga memungkinkan dapat diekspresikan untuk mengambil keputusan yang efektif atas persoalan tersebut. Persoalan yang kompleks dapat disederhanakan dan dipercepat proses pengambilan keputusannya. AHP dapat menyelesaikan masalah multikriteria yang kompleks menjadi suatu hirarki. Masalah yang kompleks dapat diartikan bahwa kriteria dari suatu masalah yang begitu banyak (multikriteria), struktur masalah yang belum jelas atau ketidakpastian pendapat dari pengambilan keputusan, pengambil keputusan lebih dari satu orang, serta ketidakakuratan data yang tersedia. Metode ini adalah sebuah kerangka untuk mengambil keputusan dengan efektif atas prinsip memecahkan persoalan dengan AHP, yaitu prinsip menyusun hirarki prinsip menentukan prioritas, dan prinsip mengukur konsistensi. Proses pengambilan keputusan pada dasarnya memilih suatu alternatif. Peralatan utama AHP adalah sebuah hirarki fungsional dengan input utamanya persepsi manusia. Dengan hirarki, suatu masalah kompleks dan tidak terstruktur dipecahkan ke dalam kelompok-kelompok. Kemudian kelompok-kelompok tersebut diatur menjadi suatu bentuk hirarki. (Nasional et al., 2013).

\section{g. Penelitian Terkait}

Dalam penyusunan skripsi ini, penulis sedikit banyak terinspirasi dan mereferensi dari penelitian-penelitian sebelumnya yang berkaitan dengan 
latar belakang masalah pada skripsi ini. Adapun penelitian yang berhubungan dengan skripsi ini antara lain yaitu: (Nasional et al., 2017) Penerapan sistem pendukung keputusan dalam pemilihan televisi berlangganan dan menggunakan metode Analytical Hierarchy Process yang dikenal dengan AHP diharapkan mampu memberikan hasil keputusan yang terbaik. Analytical Hierarchy Process merupakan suatu proses mengembangkan suatu score numeric untuk merangkingkan alternatif keputusan-keputusan yang didasarkan pada bagaimana setiap alternatif tersebut dalam memenuhi kreteria. (Sanyoto, Handayani, \& Widanengsih, 2017) Sistem pendukung keputusan dirancang untuk mendukung seluruh tahap pengambilan keputusan mulai dari mengidentifikasi masalah, memilih data yang relevan dan mentukan pendekatan yang digunakan dalam proses pengambilan keputusan sampai mengevaluasi pemilihan alternatif-alternatif yang ada. Metode yang digunakan dalam sistem pendukung keputusan ini adalah AHP (Analytical Hierarchy Process) untuk membantusistem pendukung keputusan ini adalah AHP (Analytical Hierarchy Process) untuk membantupemilihan Laptop. (Handayani \& Muzakir, 2018) Penelitian ini menggunakan metode analitytical hierarchy process (AHP), sebagai model sistem pendukung keputusan dalam penelitian ini. Dengan menggunakan metode tersebut, hasil akhir yang didapat bahwa Karyawan E berbanding dengan Karyawan B , Karyawan A , Karyawan C, Karyawan $F$ dan Karyawan D. Dari beberapa metode pendekatan yang memungkinkan, maka dipilih pendekatan Analytical Hierarchy Process. Metode ini dipilih karena metode ini menentukan nilai bobot untuk setiap atribut.

\section{Hasil dan Pembahasan}

Adapun proses pengolahan, analisa dan interprestasi data ini didahului dengan menentukan elemen-elemen yang signifikan pada masing-masing kriteria-kriteria beserta sub-sub kriterianya. Dimulai dari:

a. Penentuan tujuan utama "Pemilihan Kosmetik yang tepat".

b. Kriteria-kriteria "Harga Terjangkau, Kualitas Produk, Bahan Kosmetik".

c. Sub-sub kriteria "Harga terjangkau, Memberikan harga promo pada jumlah tertentu, Menyediakan Banyak Varian Kosmetik, Setiap Tahun Mengeluarkan Produk Terbaru, Sesuai dengan Semua Jenis Kulit, Tidak Mengandung bahan Merkuri, Bahan Pewarna Alami, Tidak mengandung bahan Hidrokinon".

Alternatif 'WARDAH, POND'S, EMINA" dari strategis penerapan dengan menggunakan metode AHP dalam pemilihan kosmetik yang tepat. Selanjutnya dilakukan untuk menjawab rumusan masalah sesuai yang diajukan berdasarkan proses hirarki analitis.

\subsection{Landasan Kriteria yang menjadi pertimbangan Pemilihan Kosmetik yang tepat Ditinjau dari Elemen Kriteria dan Sub-kriteria}

1. Berikut ini adalah bobot masing-masing kriteria yang mempengaruhi penentuan dalam pemilihan kosmetik yang tepat dari para responden:
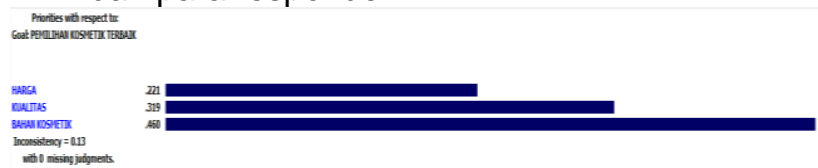

\section{Gambar 1 Kriteria beserta nilai bobotnya}

Sumber : Hasil Penelitian (2018)

2. Kriteria pertama yang mempengaruhi penentuan pemilihan kosmetik yang tepat adalah "Harga Terjangkau" (nilai bobot 0,221 atau sebanding dengan $22,1 \%$ dari total kriteria).

3. Kriteria kedua yang mempengaruhi penentuan pemilihan kosmetik yang tepat adalah "Kualitas" (nilai bobot 0,319 atau sebanding dengan $31,9 \%$ dari total kriteria).

4. Kriteria ketiga yang mempengaruhi penentuan pemilihan kosmetik yang tepat adalah "Bahan Kosmetik" (nilai bobot 0,460 atau sebanding dengan $46,0 \%$ dari total kriteria).

\subsection{Prioritas Kepentingan dari Masing- masing Variabel}


1. Kriteria dalam pemilihan kosmetik yang tepat

Dari hasil perhtiungan perbandingan berpasangan antar variabel dalam memilih Kosmetik yang tepat diperoleh prioritas kepentingan dan bobot yang ditunjukkan dalam tabel berikut ini:

Tabel I Prioritas Kepentingan Kriteria dalam Pemilihan Kosmetik yang tepat

\begin{tabular}{|l|l|l|}
\hline Kriteria & Bobot & Prioritas \\
\hline Harga terjangkau & 0,221 & $\mathrm{I}$ \\
\hline Kualitas & 0,319 & $\mathrm{II}$ \\
\hline Bahan Kosmetik & 0,460 & $\mathrm{III}$ \\
\hline
\end{tabular}

Sumber: Hasil Pengolahan AHP

\subsection{Sub-kriteria dalam pemilihan aplikasi} kosmetik yang tepat.

1. Kriteria Harga Terjangkau

Dari hasil perhitungan perbandingan berpasangan antar variabel dalam kriteria biaya premium diperoleh prioritas kepentingan dan bobot yang ditunjukkan dalam tabel berikut ini:

\section{Tabel 2.Prioritas Kepentingan Sub-kriteria Harga Terjangkau dalam Pemilihan Kosmetik yang tepat}

\begin{tabular}{|l|l|l|}
\hline Sub-kriteria & Bobot & Prioritas \\
\hline Harga Terjangkau & 0,250 & $\mathrm{I}$ \\
\hline $\begin{array}{l}\text { Menyediakan } \\
\text { Potongan Harga } \\
\text { dan Promo dalam } \\
\text { Jumlah tertentu }\end{array}$ & 0,250 & $\mathrm{II}$ \\
\hline
\end{tabular}

Sumber: Hasil Pengolahan AHP

2. Kriteria Kualitas Pelayanan

Dari hasil perhitungan perbandingan berpasangan antar variabel dalam kriteria kualitas diperoleh prioritas kepentingan dan bobot yang ditunjukkan dalam tabel berikut ini:

Tabel 3.Prioritas Kepentingan Sub-kriteria Kualitas dalam Pemilihan Kosmetik yang tepat

\begin{tabular}{|l|l|l|}
\hline Sub-kriteria banyak & Bobot & Prioritas \\
\hline $\begin{array}{l}\text { Menyediakan barian kosmetik tahun } \\
\text { varia }\end{array}$ & 0,135 & $\mathrm{I}$ \\
\hline $\begin{array}{l}\text { Setiap } \\
\text { mengeluarkan produk } \\
\text { terbaru }\end{array}$ & & \\
\hline Sesuai dengan semua & 0,281 & $\mathrm{III}$ \\
\hline
\end{tabular}

jenis kulit

Sumber: Hasil Pengolahan AHP

3. Kriteria Aplikasi

Dari hasil perhitungan perbandingan berpasangan antar variabel dalam kriteria aplikasi diperoleh prioritas kepentingan dan bobot yang ditunjukkan dalam tabel berikut ini:

Tabel 4. Prioritas Kepentingan Sub-kriteria Bahan Kosmetik dalam Pemilihan Kosmetik yang tepat

\begin{tabular}{|l|l|l|}
\hline Sub-kriteria & Bobot & Prioritas \\
\hline $\begin{array}{l}\text { Tidak mengandung } \\
\text { bahan Merkuri }\end{array}$ & 0,319 & $\mathrm{I}$ \\
\hline Bahan pewarna alami & 0,460 & $\mathrm{II}$ \\
\hline $\begin{array}{l}\text { Tidak mengandung } \\
\text { bahan Hidrokinon }\end{array}$ & 221 & $\mathrm{III}$ \\
\hline
\end{tabular}

Sumber: Hasil Pengolahan AHP

\subsection{Inconsistency Ratio(CR)}

Inconsistency ratio atau rasio inkonsistensi data responden ahli merupakan parameter yang digunakan untuk memeriksa apakah perbandingan berpasangan telah dilakukan dengan konsekuen atau tidak. Rasio inkonsistensi data dianggap baik jika nilai CRnya $\leq 0,1$. Untuk memeriksa rasio inkonsistensi data responden, berikut ini ditampilkan nilai rasio inkonsistensi pada masing-masing matriks perbandingan dari sisi Harga Terjangkau :

Tabel 5. Rasio Inkonsistensi perbandingan antara elemen matriks penggabungan data responden ahli

\begin{tabular}{|l|l|l|}
\hline No. & $\begin{array}{l}\text { Matriks Perbandingan } \\
\text { Elemen }\end{array}$ & $\begin{array}{l}\text { Nilai } \\
\text { CR }\end{array}$ \\
\hline 1. & $\begin{array}{l}\text { Perbandingan elemen } \\
\text { kriteria level 1 Harga } \\
\text { terjangkau berdasarkan } \\
\text { sasaran strategi Pemilihan } \\
\text { Kosmetik yang tepat }\end{array}$ & \\
\hline 2. & $\begin{array}{l}\text { Perbandingan elemen } \\
\text { kriteria level 2 berdasrkan } \\
\text { sasaran kriteria: Strategi } \\
\text { Harga - Harga Terjangkau }\end{array}$ & 0 \\
\hline 3. & $\begin{array}{l}\text { Perbandingan elemen } \\
\text { kriteria level 2 berdasarkan } \\
\text { sasaran kriteria: Strategi } \\
\text { Harga Terjangkau }\end{array}$ & 0 \\
& $\begin{array}{l}\text { Menyediakan Potongan } \\
\text { harga dan promo dalam } \\
\text { jumlah tertentu }\end{array}$ \\
\hline
\end{tabular}




\begin{tabular}{|c|c|c|}
\hline 4. & $\begin{array}{lr}\begin{array}{l}\text { Perbandingan } \\
\text { kriteria level } 1\end{array} & \begin{array}{r}\text { elemen } \\
\text { Kualitas } \\
\text { berdasarkan } \\
\text { sasaran }\end{array} \\
\text { Strategi } & \text { Pemilihan } \\
\text { kosmetik yang tepat }\end{array}$ & 0,13 \\
\hline 5. & $\begin{array}{l}\text { Perbandingan } \text { elemen } \\
\text { kriteria level } 2 \text { berdasarkan } \\
\text { sasaran kriteria: Strategi } \\
\text { Kualitas }- \text { Menyediakan } \\
\text { banyak varian kosmetik }\end{array}$ & 0 \\
\hline 6. & $\begin{array}{l}\text { Perbandingan } \\
\text { kriteria level } 2 \text { berdasarkan } \\
\text { sasaran kriteria: Strategi } \\
\text { Kualitas }- \text { Setiap tahun } \\
\text { mengeluarkan produk } \\
\text { terbaru }\end{array}$ & 0 \\
\hline 7. & $\begin{array}{l}\text { Perbandingan elemen } \\
\text { kriteria level } 2 \text { berdasarkan } \\
\text { sasaran kriteria: Strategi } \\
\text { Kualitas - Sesuai dengan } \\
\text { semua jenis kulit }\end{array}$ & 0 \\
\hline 8. & $\begin{array}{l}\text { Perbandingan } \\
\text { kriteria level } 1 \text { elemen } \\
\text { Kosmetik berdasarkan } \\
\text { sasaran strategi Pemilihan } \\
\text { kosmetik yang tepat }\end{array}$ & 0,13 \\
\hline 10. & $\begin{array}{l}\text { Perbandingan elemen } \\
\text { kriteria level } 2 \text { berdasarkan } \\
\text { sasaran kriteria: Strategi } \\
\text { Bahan kosmetik- Tidak } \\
\text { mengandung merkuri }\end{array}$ & 0,35 \\
\hline 11. & $\begin{array}{l}\text { Perbandingan elemen } \\
\text { kriteria level } 2 \text { berdasarkan } \\
\text { sasaran kriteria: Strategi } \\
\text { Bahan kosmetik - Bahan } \\
\text { pewarna alami }\end{array}$ & 0,05 \\
\hline 12. & $\begin{array}{lr}\text { Perbandingan } & \text { elemen } \\
\text { kriteria level } 2 \text { berdasarkan } \\
\text { sasaran kriteria: Strategi } \\
\text { Bahan kosmetik } & - \text { Tidak } \\
\text { mengandung } & \text { bahan } \\
\text { Hidrokinon } & \\
\end{array}$ & 0,05 \\
\hline
\end{tabular}

Sumber: Hasil Pengolahan AHP

Dapat disimpulkan bahwa perbandingan berpasangan yang diberikan responden ahli memiliki rasio inkonsistensi yang lebih kecil dari 0,1 sebagai batas maksimum nilai rasio inkonsistensi. Dengan demikian hasil perhitungan geometrik gabungan data responden cukup konsisten.

\subsection{Hipotesa 1}

Berdasarkan hasil Kuesioner yang telah disebarkan Penerapan Metode AHP dalam menetukan Pemilihan Kosmetik yang tepat pada Siswi SMA Taman Harapan dengan menggunakan pendekatan AHP, maka di peroleh informasi bahwa kriteria
Bahan Kosmetik adalah kriteria yang mendapat prioritas utama oleh para responden ahli dalam menentukan Pemilihan Kosmetik yang tepat dengan mendapatkan nilai bobot tertinggi dari kriteria-kriteria yang ada sebesar 0.532 atau sebanding dengan $53,2 \%$ dari total kriteria.

Selain itu sub-sub kriteria yang mendapat prioritas utama dalam Penerapan Metode AHP Pada Pemilihan Kosmetik yang tepat Untuk Siswi Muslimah pada SMA Taman Harapan adalah sub-kriteria Potongan Harga dan promo dengan nilai bobot 0,750 atau setara dengan $75,0 \%$ dari total subkriteria yang ada, selanjutnya sub-kriteria Sesuai dengan semua jenis kulit juga mendapat prioritas utama dengan nilai bobot 0,600 atau setara dengan $60,0 \%$ dari total sub kriteria yang ada. Kemudian sub-sub kriteria terakhir yang mendapat prioritas utama adalah Bahan pewarna alami dengan nilai bobot 0,460 atau setara dengan $46,0 \%$ dari total sub-kriteria yang ada. Dengan demikian dari hasil pengolahan data diatas dapat diambil informasi bahwa $(\mathrm{H} 1)$ diterima.

\subsection{Hipotesa 2}

Berdasarkan informasi yang diperoleh dari pengolahan data menunjukkan secara keseluruhan bahwa alternatif Pemilihan Kosmetik yang tepat "WARDAH" adalah alternatif yang tepat dengan pilihan yang mendapat prioritas utama dalam menentukan Pemilihan Kosmetik yang tepat dengan bobot sebesar 0,532 atau sebanding dengan 53,2\% dari total alternatif yang ada. Dengan demikian dapat ditarik kesimpulan bahwa $(\mathrm{H} 2)$ diterima.

\subsection{Perhitungan Manual - Kriteria Menggunakan Metode AHP}

Melakukan perhitungan manual dengan langkah-langkah sebagai berikut:

a. Kriteria yang menjadi penentuan yaitu, Harga Terjangkau, Kualitas dan Bahan Kosmetik.

b. Menyusun kriteria-kriteria pemilihan pemilihan kosmetik yang tepat dengan matriks perbandingan berpasangan. Masukan awal adalah menentukan nilai kriteria.

Tabel 6. Matrik Perbandingan Berpasangan

\begin{tabular}{|c|c|c|c|}
\hline Kriteria & Harga & Kualitas & $\begin{array}{c}\text { Bahan } \\
\text { kosmetik }\end{array}$ \\
\hline Harga & 1,00 & 3,00 & 5,00 \\
\hline
\end{tabular}




\begin{tabular}{|c|c|c|c|}
\hline Kualitas & 0,25 & 1,00 & 3,00 \\
\hline $\begin{array}{c}\text { Bahan } \\
\text { kosmetik }\end{array}$ & 0,5 & 0,33 & 1,00 \\
\hline Jumlah & 1,75 & 4,33 & 9,00 \\
\hline
\end{tabular}

Sumber: Pengolahan Manual AHP

c. Menjumlahkan nilai elemen setiap kolom dari nilai elemen matrik kriteria diatas, maka jumlah elemen setiap kolom adalah:

Harga : $1.00+0,25+0.5=1,75$

Kualitas: $3.00+1.00+0.33=4,33$

Bahan

kosmetik : $5.00+3.00+1.00=9.00$

d. Membagikan setiap elemen pada kolom dengan jumlah perkolom yang sesuai dari nilai-nilai elemen matriks tabel IV.6 dan jumlah masing-masing kolom diatas, maka dapat dihitung matriks normalisasinya dengan cara membagi setiap elemen pada kolom dengan jumlah perkolom yang sesuai, sebagai berikut:

Tabel 7. Matriks Normalisasi Kriteria

\begin{tabular}{|l|l|l|l|}
\hline Kriteria & \multicolumn{2}{l|}{ Perkalian } & Hasil \\
\hline Harga & $\begin{array}{l}(1,00 \times 0,55)+(3,00 \times \\
0,27)+(5,00 \times 0,17)\end{array}$ & 2,11 \\
\hline Kualitas & $\begin{array}{l}(0,33 \times 0,55)+(1,00 \times \\
0,27)+(3,00 \times 0,17)\end{array}$ & 0,71 \\
\hline $\begin{array}{l}\text { Bahan } \\
\text { kosmetik }\end{array}$ & $\begin{array}{l}(0,20 \times 0,55)+(0,33+ \\
0,27)+(1,00 \times 0,17)\end{array}$ & 0,31 \\
\hline Kriteria & Harga & Kualitas & $\begin{array}{c}\text { Bahan } \\
\text { kosmetik }\end{array}$ \\
\hline Harga & 0,57 & 0,75 & 0,33 \\
\hline Kualitas & 0,14 & 0,19 & 0,50 \\
\hline $\begin{array}{c}\text { Bahan } \\
\text { kosmetik }\end{array}$ & 0,29 & 0,06 & 0,17 \\
\hline Jumlah & 1,00 & 1,00 & 1,00 \\
\hline
\end{tabular}

Sumber: Pengolahan Manual AHP

e. Setelah matriks normalisasi didapatkan, langkah selanjutnya menunjukkan tiap baris pada matriks tersebut. Jumlah masing-masing baris pada tabel IV.7 harus 1,00 dan dapat dihitung dengan cara sebagai berikut:

Harga : $0,57+0,14+0,29=1,00$

Kualitas: $0,75+0,19+0,06=1,00$

Bahan

kosmetik:

$0,33+0,50+0,17=1,00$

Setelah didapatkan jumlah pada masing-masing baris, jumlahkan kembali baris selanjutnya dan dihitung nilai prioritas kriteria dengan cara membagi masing-masing jumlah baris dengan jumlah elemen atau jumlah kriteria, sehingga nilai prioritas masing-masing kriteria dapat dihitung sebagai berikut:

Nilai prioritas Harga : $(0,57+0,75+0,33) / 3=0,55$

Nilai prioritas

$(0,14+0,19+0,50) / 3=0,27$

Nilai prioritas Bahan kosmetik: $(0,29+0,06+0,17 / 3=0,17$

Sehingga jika dalam bentuk persen dapat dilihat pada tabel IV.8 sebagai berikut:

Tabel 8. Nilai Bobot Kriteria

\begin{tabular}{|l|l|l|}
\hline Kriteria & Bobot & Presentase \\
\hline Harga & 0,55 & $55 \%$ \\
\hline Kualitas & 0,27 & $27 \%$ \\
\hline $\begin{array}{l}\text { Bahan } \\
\text { kosmetik }\end{array}$ & 0,17 & $17 \%$ \\
\hline
\end{tabular}

Sumber: Hasil Pengolahan Manual AHP

f. Menguji konsistensi dengan cara menghitung mengalikan matriks perbandingan berpasangan awal dengan bobot prioritas kriteria, setelah itu menghitung nilai lamda maksimum dengan rumus, sebagai berikut:

Tabel 9. Perhitungan Rasio Konsistensi Mengalikan Matriks Awal dengan Bobot

Sumber: Data Pengolahan Manual AHP

Setelah dikalikan matriks awal dengan bobot lalu di bagi jumlah baris dengan bobot.

Tabel 10. Perhitungan Rasio

Konsistensi - Membagi Jumlah baris dengan Bobot

\begin{tabular}{|l|l|l|l|}
\hline Kriteria & $\begin{array}{l}\text { Jumlah } \\
\text { Baris }\end{array}$ & Bobot & $\begin{array}{l}\text { Hasil } \\
\text { Bagi }\end{array}$ \\
\hline Harga & 2,11 & 0,67 & 3,17 \\
\hline Kualitas & 0,71 & 0,23 & 3.27 \\
\hline $\begin{array}{l}\text { Bahan } \\
\text { kosmetik }\end{array}$ & 0,31 & 0,10 & 3,02 \\
\hline \multicolumn{3}{|c|}{ Average/Lambda } & 3,09 \\
\hline
\end{tabular}

Sumber: Hasil Pengolahan Manual AHP g. Menghitung indeks konsistensi (Consistency Index) dengan menggunakan rumus: $C I=\frac{\lambda_{\max -n}}{\mathrm{n}-1}$ 


$$
C I=\frac{3,09-3}{2}=0,04
$$

h. Menghitung Index Random (RI) dengan menggunakan rumus:

$$
\begin{gathered}
R I=\frac{3,09(\mathrm{n}-2)}{\mathrm{n}} \\
R I=\frac{0,04(3-2)}{3}=0,66
\end{gathered}
$$

i. Menghitung rasio konsistensi (Consistency Ratio) dengan rumus:

$$
C R=\frac{\mathrm{CI}}{\mathrm{RI}}
$$

$\mathrm{RI}$ adalah nilai indeks random dengan nilai 0,66 karena pada kasus ini mempunyai ukuran matriks 3 , sehingga nilai dari CR dapat dihitung dengan cara sebagai berikut:

$C R=\frac{0,04}{0,66}=0,07$ Karena nilai rasio konsistensi $\leq 0,1$ dan hasilnya 0,07 maka matriks dikatakan konsisten.

\section{Kesimpulan}

Output yang diharapkan dari penelitian ini adalah peringkat prioritas alternatif strategis penentuan pemilihan-pemilihan kosmetik yang tepat pada SMA Taman Harapan. Selain itu diperoleh gambaran analisa dari tingkah pengaruh masing-masing kriteria terhadap sub-kriteria dan tingkat pengaruh sub-kriteria terhadap alternatif yang diberikan pada sisi kriteria pendidikan, serta analisa dari tingkat pengaruh masing-masing kriteria terhadap alternatif yang diberikan.

Pengolahan data dilakukan dengan penelitian AHP, dikarenakan keunggulan yang dimiliki teknik analisa ini yaitu, kesatuan model tunggal yang mudah dimengerti, mampu memecahkan persoalan yang komplek, serta dapat. Saling ketergantungan elemen-elemen dalam sistem dan tidak memaksakan pemikiran yang linear.

Setelah dilakukan pengolahan data menggunakan software Expert Choice.11 maka diperoleh kesimpulan penentuan pemilihan kosmetik yang tepat dengan menggunakan Analytical Hierarchy Process dari sisi kriteria, Harga, Kualitas Produk, dan Bahan Kosmetik sebagai berikut :

a. Berdasarkan Kriteria Harga, "Sub-kriteria" yang diperlukan untuk menentukan alternatif strategi pemilihan kosmetik yang tepat yaitu:

a) Harga yang terjangkau

b) Potongan harga dan promo dari jumlah tertentu

b. Berdasarkan Kriteria Kualitas Produk, "Sub-kriteria" yang diperlukan untuk menentukan alternatif strategi pemilihan kosmetik yang tepat .
a) Menyediakan banyak varian kosmetik
b) Setiap tahun mengeluarkan produk terbaru
c) Sesuai dengan semua jenis kulit

c. Berdasarkan Kriteria Bahan Kosmetik, "Sub-kriteria" yang diperlukan untuk menentukan alternatif strategi pemilihan kosmetik yang tepat
a) Tidak mengandung merkuri
b) Bahan pewarna alami
c) Tidak mengandung bahan Hidrokinon

d. Berdasarkan ketiga kriteria Harga, Kualitas, Bahan Kosmetik yang diperlukan untuk menentukan alternatif strategi pemilihan kosmetik yang tepat .
a) Wardah
b) Pond's
c) Emina
Berdasarkan rasio Harga, Kualitas Produk, dan Bahan Kosmetik, Wardah kosmetik merupakan prioritas utama dari alternatif strategis yang diambil sebagai penerapan Pemilihan Kosmetik yang tepat yang dibuktikan melalui pengolahan data responden disusul urutannya berikut, Wardah, Pond's, Emina. Dengan dilakukannya penelitian ini maka straregi Pemilihan Kosmetik Ternaik dengan menggunakan metode AHP menggunakan software Expert Choice 11 dapat diterapkan di SMA Taman Harapan dan hasil akhirnya adalah pemilihan Kosmetik Wardah sebagai prioritas utama dari alternatif strategis yang diambil.

\section{Referensi}

Fachrurrazi, S., Informatika, T., Informasi, S., Malikussaleh, U., Utara, A., Langsat, K., ... Kosmetik, H. (n.d.). Jurnal Sistem Informasi ISSN: 2598-599X Sistem Pendukung Keputusan Pemilihan Perempuan Indonesia Menggunakan Jurnal Sistem Informasi ISSN: 2598599X, 97-126.

Handayani, R. I. (2016). Sistem pendukung keputusan pemilihan laptop untuk karyawan pada pt. Indotekno dengan menggunakan metode analitycal hierarchy process, 2(1), 5-10.

Handayani, R. I., \& Muzakir, A. (2018). Sistem Pendukung Keputusan Penerimaan Karyawan Dengan Menggunakan Metode Analytical Hierarchy Process (Ahp) Studi Kasus: Pt. Virtus Venturama. Jurnal Pilar Nusa Mandiri, 14(1), 43-48. Retrieved from http://ejournal.nusamandiri.ac.id/ejurnal/i ndex.php/pilar/article/view/734/pdf 
Indika, D. R., \& Lainufar, S. (2015). Eksplorasi sikap konsumen terhadap kosmetik halal (studi kasus:wardah), 55-64.

Nasional, K., Sosial, I., Tjipta, H., Wasiyanti, S., Berprestasi, P. K., \& Rijayana, M. (2017). Metode Analytical Hierarchy Process ( Ahp ), 1(2), 361-367.

Penelitian, L., \& Pengaruh, A. A. (2018). Jurnal Riset Sains Manajemen, 2, 1-8. https://doi.org/10.5281/zenodo.1236827

Permata, B. I., Prihatini, A. E., Advertisement, Y., Loyalty, C., Technology, P., Youtube, P., ... Diponegoro, U. (2017)..

Rahmawati, V. (2014). Pengaruh Atribut Produk dan Label Halal Sebagai Variabel Moderating Terhadap Keputusan Pembelian Produk Kosmetik Wardah di Kota Semarang.

Sanyoto, G. P., Handayani, R. I., \& Widanengsih, E. (2017). Sistem Pendukung Keputusan Pemilihan Laptop Untuk Kebutuhan Operasional Dengan Metode Ahp (Studi Kasus: Direktorat Pembinaan Kursus Dan Pelatihan Kemdikbud). Jurnal Pilar Nusa Mandiri, 13(2), 167-174.

Taufiq, R., \& Fahrozi, N. F. (2016). Perancangan Sistem Pendukung Keputusan ( SPK ) Pemilihan Kendaraan Alat Berat Tambang Batubara dengan Metode Analytical Hierarchy Process ( AHP ). Scientium, 3, 94-107. 